\title{
Teaching stress management in undergraduate dental education: are we doing enough?
}

\author{
J. M. Colley, ${ }^{1}$ M. Harris, ${ }^{2}$ P. Hellyer ${ }^{3}$ and D. R. Radford ${ }^{* 4}$
}

\section{Key points}

Questions whether we as a profession are doing enough to prepare undergraduates for the stress of a professional life.
Presents findings of a short intervention provided for students at the University of Portsmouth Dental Academy
Highlights how some recent students view and cope with stress.

Dentistry is recognised as a stressful profession. A number of studies focusing on undergraduate education have shown high levels of stress in dental students. However, despite calls to do so, little has been published on methods to teach future dental professionals about stress and how to manage it on a personal level. Psychological stress which is uncontrolled may have an effect on general health. It is recognised, however, that stress can be beneficial if channelled appropriately. Techniques and ways to teach management of potential stresses of a career in dentistry have still not been widely reported in either dental undergraduate or postgraduate education. An intervention used with final year dental students at the University of Portsmouth for the last four years has highlighted some of the problems raised by students coping with a stressful programme of study. Students' comments indicated the need for an educational intervention on recognising and reducing stress to be introduced earlier on in their curriculum and that it should be universally taught.

\section{The problem}

Stress in our undergraduate students

For dental students, the dental school curriculum and environment is known to be highly demanding and a stressful learning experience. ${ }^{1}$ This is primarily due to the early clinical exposure and the style of an academic apprenticeship that many programmes adopt, that is, the students are exposed to the demands of clinical dentistry early in the programme combined with the academic requirements of an intensive five-year programme. A number of studies have demonstrated the impact of stress on dental students, and perceived sources of stress in diverse academic settings. ${ }^{2-4}$ The top stress-provoking factors have been reported as examinations and grades, workload, patient care, and graduation requirements. ${ }^{5,6}$ Some students reported feeling

${ }^{1}$ Clinical Teacher, University of Portsmouth Dental Academy and King's College London Dental Institute; ${ }^{2} \mathrm{PhD}$ student, University of Portsmouth Dental Academy; ${ }^{3}$ Honorary Teaching Fellow, University of Portsmouth Dental Academy; ${ }^{4}$ Reader, Hon Consultant, Integrated Dental Education and Multi-Professional Care; King's College London Dental Institute and the University Portsmouth Dental Academy ${ }^{*}$ Correspondence to: Dr David R. Radford

Email: david.radford@kcl.ac.uk

Refereed Paper. Accepted 19 December 2017

DOI: $10.1038 /$ sj.bdj.2018.220 overwhelmed by their experience in dental school to the extent that their physical and mental health, as well as their social life, was negatively affected. ${ }^{7}$ A recent study by Turner et al. ${ }^{8}$ showed that Year 5 students reported greater perceived stress than Year 1 students. Moreover, they found that non-course-related sources of stress which included difficulties with a journey to university, family responsibilities, money and social distractions also affected preparation for examinations. ${ }^{8}$ Despite the volume of research in investigating levels and reasons for stress in dental students, little has been reported on how to provide dental students with the tools to manage stress. Further and most importantly Kay and Lowe ${ }^{9}$ concluded that, as preparation for life as a dentist occurs at university, stress management and professional and personal awareness education needs to be included in the undergraduate curriculum in order to reduce or address threats to physical or mental well-being as a dental professional. The students who are stressed by the clinical/ academic mix and life events at university may also be those that will be stressed as dentists. Why is there so scant literature on this area of managing stress in our profession? Is it that either the issues are still not being addressed in dental schools or if it is happening, it is considered not worthwhile to report on?
It is hoped that this opinion paper will act as a catalyst for a more widespread debate in the profession and among dental educators as to whether we are doing enough to prepare our future colleagues not just for the undoubted stress of dental school but more importantly for dental practice. Last is to challenge people who anecdotally are trying to address the problem to publish more widely so we can all learn from best practice.

\section{A possible partial solution}

What we do at the University of Portsmouth Dental Academy (UPDA)

UPDA acts as host to final year students from King's College London Dental Institute (KCLDI) in an outreach setting in primary dental care. ${ }^{10}$ During the first week of attendance at UPDA at the start of their final year, students are familiarised with the clinical environment, the computerised patient management system and working within the NHS dental contract. In addition, a brief intervention that had been piloted at UPDA $^{11}$ has been subsequently implemented for the last four years to educate final year dental students to identify and recognise stress. The intervention suggests possible tools to manage stress, in order for the students to have a healthy productive career. In the last session of their 
induction week, a two hour seminar is delivered focusing on the introduction of stress awareness as a professional and how to develop coping strategies. The objective is to stimulate students to consider that in their final year of study, they may be challenged by both short-term and long-term stressors. In addition, beyond graduation, dentistry could continue to be stressful. ${ }^{9}$ In order to counter some of the negative effects of this stress, it is suggested that coping mechanisms should be considered at this early stage of their careers.

The session is introduced by a highly experienced dental practitioner (JMC) who has had experience of over 40 years in the profession, of which he has been a GDP, clinical teacher and mentor to dentists in practice. He considers the positive aspects of the profession but also some of the price that is consequent, that is, managing patients who are in pain and stressed, the need to be running a profitable business and the cumulative effects that this might have. He introduces the concept that unless the students care for themselves, they cannot effectively care for their patients, which is the first principle of the GDC; 'Put patients' interests first. ${ }^{\text {.2 }}$

Through anecdotes to which he feels the students can relate, JMC introduces various techniques that he has adopted that have proven useful to himself during his career, with the recognition that some may be adopted, some will certainly be rejected and some may build on already successful practices or modified to suit the individual student. These include:-

- Writing problems down, as opposed to going through the situation time and again in their head. An example would be to ask a newly qualified dentist who was going through a phase of their ID nerve blocks not seeming to be effective, to jot down the numbers of times they have had of success of giving an ID block compared to lack of success. This can help in trying to get acute problems in perspective

- The anxiety that procrastination can cause when a difficult situation has to be addressed. Resisting the temptation to cancel a difficult patient, for instance, knowing full well that the problem will simply have to be addressed on another occasion

- Ordering the clinical sequence of work where possible - that is, to do the difficult restoration at the first appointment, so that there is not a week to worry about doing it next week

- Creating barriers or thresholds between 'work life' and 'home life' (for instance, making constructive use of the journey to and from work as a threshold)
- Starting the day with a positive frame of mind - eg, 'today is going to be a good day'.

Last, he introduces the concept of meditation, what it involves and why it may be beneficial. He invites the students to join him in a guided meditation session. ${ }^{13}$ He finishes the session with a general discussion inviting the students to comment from their experience of life and of being a dental student over the last four years and concludes with the notion that 'dentistry is important but not as important as your wellbeing and happiness'.

\section{What were the students' thoughts of} the intervention ten months after it was delivered?

The feedback from the students at the end of their Portsmouth placement provided some insightful comments and certain themes emerged. Some of the students had not revisited the suggested methods of coping with stress as they reported that either they were not stressed or have already adopted other coping mechanisms, for example, using stretching exercises or Pilates as a coping mechanism to stress.

Of those students who had revisited the techniques, some suggested that it should be adopted earlier in the programme, as they considered that stress plays such an integral part of their lives as students/dentists, but either that stress was not recognised, forgotten all together or 'brushed under the carpet.' Furthermore, the students felt that before their stress management training at UPDA, they were unsure how to channel it positively or control it, and wished that they had been aware of these concepts throughout their five years. They also felt that it should be universally taught. It can be argued that introduction to these techniques in Year 5 is too late and earlier introduction when the students have some clinical commitment might be more appropriate.

Another theme that emerged was that students had been told that dentistry was stressful often by very senior dental professionals. Appreciating this fact, the students described how they used JMC's techniques and concepts to allow themselves to put their 'lives in general in context' to consider which parts of their lives were going well and to think positively about their future goals of being a good clinician, and 'achieving happiness'. There is a need to teach students about identifying and coping with stress rather than just telling them they will be stressed, which was reiterated by the students' recommendations that stress management interventions should be introduced as part of the undergraduate curriculum.
The last theme of 'no time to do so and additional help required' is of particular interest. This theme reflected the issues of timetabling constraints and confidence in techniques hampering students' engagement in 'optimal' meditation and relaxation techniques sessions offered by JMC. The undergraduate curriculum is already very intensely utilised, ${ }^{14}$ particularly in an outreach setting. However, many mindfulness and meditation courses offered in the private sector are of up to $12-15$ sessions and would have significant cost and time implications for often overstretched educational budgets. This has to be combined with us preparing our students for the future so it is necessary to find the time in the curriculum as some were already looking to the future, recognising that dental foundation training (DFT) and beyond would bring 'lots of new situations to deal with'

\section{Overall discussion and conclusions}

Low psychological well-being among students in higher education

Mental illnesses, mental distress, and low psychological well-being among students in higher education in the UK are increasing. ${ }^{15}$ If the student population is a reflection of the entire UK population, in which a significant number of young adults with mental health needs have been unable to access support and treatment before enrolling at university, it should not be too surprising that students with susceptibility to mental health issues thus remain vulnerable when they enter their new world of academia. Indeed, a recent report by the Institute for Public Policy Research has called for a 'whole-university approach' to promote mental health and well-being among university students, so that they can thrive and reach their full potential. ${ }^{15}$ The dental programme is academically highly demanding with the added dimension of early patient contact. This is combined with a general consensus that 'dentistry is stressful' with some of the student responses reporting there was a tendency for senior dentists to talk this up. The reasons for this are not obvious but may be benign, as a warning to younger dental professionals of the risks of the career, or possibly as a rather macho 'look what I've coped with attitude. In our opinion it would be preferable for more experienced dental professionals and dental educators to recognise that there are stressors of different types, and that these need to be managed. Coping mechanisms should be encouraged and embedded from an earlier 
stage in the undergraduate curriculum much the same way as we do with 'professionalism' and 'reflective learning', recognising that stress managed well, can be of benefit to the practising dental profession. Fortunately, in the delivery of comprehensive healthcare, there is an increasing recognition of the critical place of mental health and social well-being and thus it is becoming a less taboo subject. ${ }^{16}$ However, unfortunately, the recently published 'The graduating European dentist' which states that it provides a new approach that reflects best academic practice in European dental education, fails to discuss the need to teach and embed resilience and management of stress in the dental curriculum. ${ }^{17}$

\section{Timing of intervention}

Some students felt that the intervention to cope with stress was too late in the programme when introduced in the final year. One could argue that it could be introduced in Year 1, but at that stage as the students only have minimal clinical exposure the sessions may not be well received and the impact would not be so useful. A possible compromise would be to introduce the intervention when the students are beyond initial clinical contact and undertaking significant work in the clinic in Year 3. The logistics of this in an already packed curriculum would be significant and the staff offering the sessions would need to have considerable 'buy in' and understand some of the science behind stress. Further, the intervention would need to be fully evaluated, as if introduced too early in the programme, students may well just dismiss the concepts as they had not experienced many of the stressors in providing dental care. Clinical dentistry is all new and exciting at first in a very controlled environment!

\section{Effectiveness of meditation}

There is an emerging literature as to the effectiveness of meditation-style practices reporting on both randomised controlled trials of students who are seeking help for stress ${ }^{18}$ and of medical students as part of their education. ${ }^{19}$ The trail of 'Koru', which is a short intervention of only four, 75 minute sessions with participants spending ten minutes daily in mediation practice, was shown to be effective at reducing symptoms of stress and enhancing psychological well-being. ${ }^{18}$ Further, a recent systematic review has suggested that short interventions (eight week programmes of mindfulness based stress reduction) involves changes on both the function and structure of the brain giving some understanding of the neurobiological explanation for stress reduction training. ${ }^{20}$ Lastly, some limited studies into interventions for GDPs under stress have been reported ${ }^{21}$ and most recently a self-help training CPD package for GDPs was reported as being well received and effective. ${ }^{22}$

\section{Goal setting}

Positively functioning individuals will have goals, direction and purpose, providing a sense of meaning in their lives and will take advantage of environmental opportunities, including stressful events, to continue to develop and grow. Therefore, in our opinion we should not shy away from exposing students to rigorous assessment and challenging clinical situations, as it is most likely that as dental professionals they will use goal setting as a means of increasing their engagement in living a meaningful life. Goal setting has not been considered as part of this intervention used at UPDA for dental students, but is being introduced for hygiene and therapy students at UPDA, and further research in its use would be appropriate, particularly in the context of future careers. Certainly, some students reflected that the lessons learnt may help with coping with stress in foundation training and beyond. Within the nature of the undergraduate curriculum, the timing of goals including term-time assignments and end-ofyear examinations are in the hands of the dental school, but additional assessments such as the dental foundation training assessment process are instituted by others and consequently may be a cause of further stress when the students are already under considerable pressure.

In conclusion, this opinion paper was prompted by an intervention to teach final year students how to recognise and develop strategies on how to cope with stress in their programme. Despite the limitations of the intervention, it has been shown to have been well received. Some students expressed a need for it to be introduced and embedded earlier on in their programme and that it should be universally taught. It is recognised that some stress, however, is beneficial and the concept of the journey to self-set goals as a benefit in combatting stress needs further research in the context of dentistry and dental education. That dentistry is a stressful occupation is well recognised, but techniques to manage that stress in both undergraduate and postgraduate settings have not been widely reported on and the authors believe that the dental professional should be more proactive in addressing this potentially career-damaging issue.
Acknowledgements

The authors would like to acknowledge all the staff and student colleagues at the University of Portsmouth Dental Academy in creating an environment that encourages novel educational initiatives and in particular Dr Clare Wilson (School of Psychology, University of Portsmouth) and Professor Chris Louca for his constructive comments of this manuscript.

1. Al-Samadani K H, Al-Dharrab A. The perception of stress among clinical dental students. World J Dent 2013; 4: 24-28.

2. Humphris G, Blinkhorn A, Freeman R et al. Psychological stress in undergraduate dental students: baseline results from seven European dental schools. Eur J Dent Educ 2002; 6: 22-29.

3. Gorter R, Hammen S, Freeman R, Murtomaa H, Blinkhorn A, Humphris G. Psychological stress and health in undergraduate dental students: fifth year outcomes compared with first year baseline results from five European dental schools. Eur J Dent Educ 2008; 12: 61-68.

4. Divaris K, Barlow P J, Chendea S A et al. The academic environment; the students' perspective. Eur J Dent Educ 2008; 12: 120-130.

5. Alzahem A M, Alaujan A H, Van der Molen H T, Schmidt $H \mathrm{G}$, Zamakhshary M H. Stress among dental students: a systematic review. Eur J Dent Educ 2011; 15: 8-18.

6. Elani H W, Allison P J, Kumar R A et al. A systematic review of stress in dental students. J Dent Educ 2014; 78: 226-242.

7. Dahan H, Bedos C. A typology of dental students according to their experience of stress: a qualitative study. J Dent Educ 2010; 74: 95-103.

8. Turner J. Bartlett D, Andiappan M, Cabot L. Students' perceived stress and perception of barriers to effective study: impact on academic performance in examinations. Br Dent J 219: 453-458.

9. Kay E J, Lowe J C. A survey of stress level, self-perceived health and health-related behaviours of dental practitioners in 2005. Br Dent J 2007; 204: E19.

10. Radford D R, Holmes S, Dunne S M, Woolford M J. Outreach clinical dental education; the Portsmouth experience-a four year follow up study. Eur J Dent Educ 2016; 20: 148-155.

11. Radford D R, Colley J M, Hellyer P. Teaching stress management Br Dent J 2014: 216: 49

12. General Dental Council. Standards for the Dental Team. 2013. Available https://www.gdc-uk.org/professionals/ standards/team (accessed May 2016).

13. The Honest Guys. Guided meditation-Deep relaxation. 2011. Available at https://www.youtube.com/ watch?v=Jyy0ra2WcQQ (accessed February 2018).

14. Pyle M A. New models of dental education and curricular change: their potential impact on dental education. J Dent Educ 2012; 76: 89-97.

15. Thorley C. Not by Degrees: Improving student mental health in the UK's Universities. 2017. Available at https://www. ippr.org/research/publications/not-by-degrees (accessed September 2017).

16. Saxena S, Funk M, Chisholm N. World Health Assembly adopts comprehensive mental health action plan 2013-2020. Lancet 2013; 381: 1970-1971.

17. Field J C, Cowpe J G, Walmsley A D. The graduating European dentist: A new undergraduate curriculum framework. Eur J Dent Educ 2017; 21 (suppl. 1): 2-10.

18. Greeson J M, Juberg M K, Maytan M, James K, Rogers $H$. A randomized controlled trail of Koru: a mindfulness programme for college students and other emerging adults. J Am Coll HIth 2014; 62: 222-233.

19. Rosenzweig S, Reibel D K, Greeson J M, Brainard G C, Hojat M. Mindfulness-based stress reduction lowers psychological distress in medical students. Teach Learn Med 2003; 15: 88-92.

20. Gotink R A, Meijboom R, Vernooij M W, Smits M, Hunink M G M. 8-week mindfulness based stress reduction induces brain changes similar to traditional long-term meditation practice - A systematic review. Brain Cog 2016; 108: $32-41$.

21. Newton J T, Allen C D, Coates J, Turner A, Prior J. How to reduce the stress of general dental practice: the need for research into the effectiveness of multifaceted interventions. Br Dent J 2006; 200: 437-440.

22. Chapman H R, Chipchase S Y, Bretherton R. The evaluation of a continuing professional development package for primary care dentists designed to reduce stress, build resilience and improve clinical decision-making. Br Dent $J$ 2017; 223: 261-271. 